\title{
PESQUISA E PRÁTICA NA FORMAÇÃO UNIVERSITÁRIA: REFLEXÕES SOBRE O ESTÁGIO EM CLÍNICA PSICANALÍTICA NO SERVIÇO DE PSICOLOGIA APLICADA
}

\author{
RESEARCH AND PRACTICE IN THE UNIVERSITY EDUCATION: \\ REFLEXIONS ABOUT THE PSYCHOANALYTICAL CLINIC INTERNSHIP \\ IN THE SERVICE OF APPLIED PSYCHOLOGY
}

\author{
Ingrid Vorsatz ${ }^{1}$ \\ Renata Dahwache Martins ${ }^{2}$ \\ Brenda Castro Gomes ${ }^{3}$ \\ Cynthia Silva dos Santos ${ }^{4}$
}

[...] decidimos nada simplificar e nada ocultar. Se não conseguirmos ver as coisas claramente, pelo menos veremos claramente quais são as obscuridades.

(FREUD, 2014)

\begin{abstract}
Resumo: Em 1912, Freud afirma categoricamente que no que tange à psicanálise, pesquisa e tratamento coincidem. O presente artigo objetiva discutir esta afirmação à luz das premissas que orientam uma pesquisa de caráter qualitativo, cujo campo aqui privilegiado será o da clínica. A partir de uma revisão sucinta dos artigos freudianos onde o binômio pesquisa e clínica psicanalítica são problematizados, pretendemos discutir em quê a clínica pode ser considerada como um campo de investigação, no qual teoria e prática são indissociáveis. Por fim, abordaremos esta problemática a partir da prática em estágio supervisionado de orientação psicanalítica no Serviço de Psicologia Aplicada da Universidade do Estado do Rio de Janeiro, onde verificou-se possível fazer a experiência da clínica como campo de pesquisa, sobre a qual pretendemos testemunhar. Apesar das dificuldades inerentes à estrutura acadêmica para prática da psicanálise tout court no âmbito de uma clínica-escola, a experiência de estágio supervisionado em clínica psicanalítica se sustenta sobre os seus pilares fundamentais, constituindo uma experiência formadora, no sentido forte do termo.
\end{abstract}

Palavras-chave: Formação universitária; Pesquisa; Metodologia; Clínica psicanalítica; Experiência.

\footnotetext{
${ }^{1}$ Doutora em Teoria Psicanalítica pela Universidade Federal do Rio de Janeiro (UFRJ). Professora Adjunta do Instituto de Psicologia da Universidade do Estado do Rio de Janeiro. Professora colaboradora do Programa de Pós-graduação em Psicologia Social (IP-UERJ). Coordenadora do Curso de Especialização em Psicologia Clínica Institucional - Modalidade Residência Hospitalar (IP-UERJ). Coordenadora da Comissão de Residência Multiprofissional e em Área Profissional de Saúde da Universidade do Estado do Rio de Janeiro (COREMU-UERJ), Rio de Janiero, Brasil. E-mail: ingrid.vorsatz@ uerj.br

${ }^{2}$ Graduada em Psicologia pela Universidade do Estado do Rio de Janeiro (UERJ), Rio de Janeiro, Brasil. E-mail: rdahwache@ gmail.com

${ }^{3}$ Graduanda em Psicologia pela Universidade do Estado do Rio de Janeiro (UERJ), Rio de Janeiro, Brasil. E-mail: brenda.cg1993@gmail.com

${ }^{4}$ Graduanda em Psicologia pela Universidade do Estado do Rio de Janeiro (UERJ), Rio de Janeiro, Brasil. E-mail: cynthiaadb@hotmail.com
} 


\begin{abstract}
In 1912, Freud categorically states that, regarding psychoanalysis, research and treatment coincide. This article aims to discuss this statement in the light of the premises that guide a qualitative research, whose privileged field shall be the clinics. From a brief review of Freudian articles where the binomial research and clinics are problematized, we intend to discuss in what the clinics can be considered as a field of investigation, in which theory and practice are inseparable. At last, we address this problematic from the practice at a supervised internship under a psychoanalytical direction in the Service of Applied Psychology of Rio de Janeiro State University, where it was found ti be possible to make the clinical experience as a research field, on which we intend to testify. Despite the difficulties due to the academic structure to the psychoanalytical practice tout court within the scope of a school-clinic, the supervised internship experience in the psychoanalytical clinic stands on its fundamental pillars, constituting a formative experience, in the strong sense of the term.
\end{abstract}

Keywords: Univesity education; Research; Methodology; Psychoanalytical clinics; Experience.

\title{
1 Introdução
}

Uma pesquisa que se pretenda científica deverá, necessariamente, incluir em seu escopo uma opção metodológica que guiará o caminho a ser percorrido, bem como uma discussão a partir de um referencial teórico posterior à análise e aos resultados obtidos (SILVA; HERZBERG; MATOS, 2015; GERHARDT; SOUZA, 2009). A metodologia mostra-se um elemento crucial, pois revela a necessidade de investigar e de responder a uma questão-problema. Conforme apontam Silva, Herzberg e Matos (2015), é o método escolhido pelo pesquisador que fornece o caminho para responder o questionamento levantado, permitindo que o conhecimento científico se diferencie do senso comum. A teoria, por sua vez, confere um conjunto de regras coerentes entre si que salvaguarda a problematização pretendida, podendo ser considerada como uma forma de produção de pensamento, sempre em vias de explicar o fato ou fenômeno pesquisado, conforme destacado por Pinto (2004).

Silva, Herzberg e Matos (2015) assinalam que apenas há pouco mais de um século surgiram os métodos qualitativos de pesquisa, que presumem analisar a realidade de forma não quantificável e objetificada. Silveira e Códova (2009) definem a pesquisa qualitativa, pautada nas especificidades das ciências sociais, como sendo oposta à concepção de que haja um modelo uniforme de pesquisa para todas as ciências. Os referidos autores pressupõem haver uma metodologia própria às ciências humanas e sociais e recusam o modelo positivista e quantitativo aplicado à vida social. Desta forma, a pesquisa qualitativa visaria explicar os fenômenos e aspectos da realidade sem quantificá-los; antes, deverá proceder analisando-os e explicando-os a partir de uma concepção das relações sociais como dinâmicas, mutáveis e singulares (SILVEIRA; CÓDOVA, 2009). 
De acordo com Pinto (2004), em relação à psicologia enquanto integrante do campo das ciências humanas, haveria uma interferência dos aspectos sócio-culturais tanto internos, referentes ao próprio sujeito, quanto externos, isto é, concernentes à cultura em geral, que, inevitavelmente, afetariam a visão do pesquisador e, consequentemente, a própria construção da pesquisa, considerando a implicação do pesquisador imprescindível para a mesma. Tal complexidade de fatores se tornaria ainda mais intensificada no que diz respeito à psicologia clínica, quando adotada como modelo qualitativo de pesquisa.

Ainda de acordo com a autora, a clínica enquanto metodologia de investigação implicaria em um processo dinâmico de estudo, considerando a própria ciência como um construto da subjetividade humana, contida em um determinado aparato teórico. Esta modalidade de pesquisa apresentaria uma epistemologia específica, em que a investigação seria construída através da experiência com o fenômeno estudado, por meio de uma "pesquisa-ação" (PINTO, 2004, p. 75). Isto é, o pesquisador não assume lugar de apenas um observador, mas se inclui e considera seus aspectos psicossociais na análise de resultados e que, sobretudo, visa mudanças concretas sobre o objeto de pesquisa, já que parte do pressuposto de que é impossível pesquisar sobre um objeto sem atingi-lo de alguma forma.

De outra parte, Lopes (2011) indica que a pesquisa em psicanálise não pode ser tomada, a rigor, como sendo quantitativa nem qualitativa, pois, ainda que a pesquisa qualitativa promova mudança radical na metodologia em pesquisa, ambas visam uma formalização do conhecimento. A pesquisa em psicanálise, por sua vez, colocaria em jogo o próprio saber, deslocando-o de seu lugar apaziguador de garantir de certezas.

Blanchot (2010) ao se indagar sobre o que é uma questão, encaminha o debate afirmando que esta diz respeito a uma procura, a uma pesquisa. Para este autor, questionar seria avançar sobre o horizonte do problema, mantendo-o em movimento. A questão caracterizaria uma abertura e, nesse sentido, é categórica: a resposta nada mais é do que a infelicidade, a adversidade da pergunta - já que em seu propósito mesmo, a resposta cala e trai sua questão. Assim, podemos entender que o saber apazigua as questões e fecha-se hermeticamente a qualquer tipo de movimento.

A psicanálise, ao deslocar o saber de seu lugar de tamponamento de questões, faz retornar sobre si - e, consequentemente, sobre o praticante -, as questões advindas da própria prática. Desta forma, trata-se de um trabalho que não isola teoria e prática, mas as remete a um estatuto de indissociabilidade, constitutivo do próprio campo, como Freud 
(2010a) indicara em um de seus artigos sobre o método clínico próprio da psicanálise. (LOPES, 2011). Desenvolveremos essa questão mais adiante.

De acordo com Kuhn, uma pesquisa científica deveria estar "firmemente baseada em uma ou mais realizações científicas passadas expostas e relatadas em manuais científicos elementares ou avançados” (KUHN apud PRUDENTE; RIBEIRO, 2005, p. 59). Assim, uma teoria seria considerada científica apenas se os seus critérios forem objetivos.

Em relação ao que pretendemos discutir no presente trabalho, ao apresentar a psicanálise como uma ciência, Freud promove um corte epistemológico paradigmático, visto que seus pressupostos anunciam que essa ciência se ocupa, sobretudo, da singularidade (PRUDENTE; RIBEIRO, 2005). Sob a ótica da cientificidade do século XIX, a experiência do sujeito e sua história não eram considerados dados suficientemente legítimos, ou ainda dignos de credibilidade científica. Todavia, Freud nunca cedeu do intento em alinhar a psicanálise à ciência. Aponta que, com frequência, se depara com a afirmação de seus pares de que as ciências devem ser alicerçadas em conceitos claros e bem definidos. Porém, o primeiro objetivo de uma atividade científica, para Freud, é o de descrever o fenômeno, sendo impossível evitar que nessa descrição se apliquem certas ideias abstratas, "ideias vindas daqui e dali" (FREUD, 2010b). Ainda que haja a construção de ideias abstratas, estas não concernem ao inefável; antes, dizem respeito aos efeitos inantecipáveis obtidos através da experiência em sua dimensão real, que sustentam seu método clínico de investigação.

A partir dos aspectos indicados a respeito de uma pesquisa qualitativa que propõe a clínica como campo privilegiado de investigação, bem como da experiência enquanto estagiárias do Serviço de Psicologia Aplicada do Instituto de Psicologia da Universidade do Estado do Rio de Janeiro (SPA-UERJ) inseridas em uma equipe cuja supervisão clínica é de orientação psicanalítica, pretende-se discutir a afirmação de Freud de que, no que tange a psicanálise, pesquisa e tratamento coincidem (FREUD, 2010a). De acordo com a orientação do próprio Freud (1993a) de que para tratar da psicanálise é imprescindível situar a sua história e os seus caminhos, retomaremos de forma sucinta a proposta freudiana da clínica enquanto campo privilegiado de investigação. Para tanto, remontaremos aos primórdios da constituição do campo psicanalítico, indiscernível tanto de seu método como da especificidade do tratamento proposto, ambos decorrentes da formulação do conceito de Inconsciente (FREUD, 1993b). Desta forma, visamos situar os pontos de inflexão nos quais a clínica revela sua dimensão de descoberta, vale dizer de 
criação de um novo campo de pesquisa e de sua aplicação. Em seguida, discutiremos de forma concisa como Freud concebe a relação entre psicanálise e ciência, sobretudo no que diz respeito à pesquisa clínica.

Por fim, pretendemos abordar a clínica como campo de pesquisa em psicanálise através da experiência singular no estágio supervisionado em clínica que vem sendo realizado no SPA-IP-UERJ, procurando articular de que forma é possível sustentar uma prática em estágio supervisionado de orientação psicanalítica na universidade, assim como assinalando seus impasses e limitações. Para tanto, será discutida a metodologia de supervisão adotada, proposta e sustentada pela professora-supervisora, de forma a problematizar que é possível realizar um trabalho clínico no âmbito de uma instituição universitária. Procuramos ainda assinalar, a partir de nossa experiência de estágio e de acordo com o que testemunhamos em nossa prática, em que medida tratamento e pesquisa coincidem em psicanálise, conforme a relevante indicação freudiana.

\section{A clínica como campo privilegiado de investigação: a proposta freudiana}

Em relação à psicanálise, Freud (2010a) adverte que não é desejável trabalhar cientificamente sobre um caso em atendimento sem que tenha havido a conclusão do tratamento, visto que nas situações em que a utilidade científica se encontra em primeiro plano, a perspectiva clínica é obscurecida. A atitude psicanalítica seria a de deixar-se surpreender pelo que a clínica apresenta, sem preconcepções. Desse modo, não há porquê distinguir o procedimento clínico daquele de pesquisa, visto que, em psicanálise, tratamento e pesquisa coincidem.

Uma década mais tarde, Freud define a psicanálise como: 1) um método de investigação do inconsciente; 2) um método de tratamento, baseado na investigação propriamente clínica; 3) uma coleta de informações que, a partir deste método que conjuga tratamento e pesquisa, se acumulam em uma disciplina inteiramente nova. A definição freudiana ressalta que, em sua nova ciência, parte-se do fenômeno clínico portanto, singular - para a constituição de uma proposição de validade universal, consoante o método científico (FREUD, 1993a)

A primeira grande revolução suscitada pela psicanálise ocorre com a descoberta da determinação inconsciente sobre as ações humanas e da sexualidade infantil. Ao criar o método da escuta do inconsciente através do postulado da associação livre [Einfall], Freud rompe com o paradigma vigente na medicina da época, que tinha o funcionamento 
do organismo como objeto principal de seu estudo, considerando a doença decorrente de causas puramente orgânicas. A medicina do século XIX concedia todo privilégio à anatomia patológica, justamente aquilo que é contrariado pelo sintoma histérico - por exemplo, paralisias motoras na ausência de uma lesão anatômica correspondente.

A psicanálise é legitimada como ciência através de seu objeto teórico, o inconsciente, através do corte epistemológico com a tradição da psicologia da consciência e com a psiquiatria do final do século XIX e início do século XX (PRUDENTE; RIBEIRO, 2005). A partir da conceituação do inconsciente enquanto um sistema psíquico determinante de atos psíquicos até então considerados irrelevantes - tais como o sonho, o lapso, o chiste e o sintoma histérico -, Freud pressupõe um sujeito que não mais é unívoco (como unidade indivisível), mas, sim, dividido, opaco a si mesmo. Vejamos, a seguir, de que forma a clínica se impõe a Freud em sua dimensão de descoberta.

\subsection{Clínica e pesquisa na criação da psicanálise}

O jovem Freud, recém-graduado em medicina e especializado em neurologia teve seu caminho atravessado pelo enigma que a histeria impunha à medicina da época. Realizou um estágio no Hospital de La Salpetrière, em Paris, no serviço de Charcot, médico francês dedicado ao estudo dos sintomas das "doenças dos nervos". Este encontro foi decisivo e marcou o caminho futuro de Freud rumo à clínica, que até então se dedicara aos estudos laboratoriais, (FREUD, 1993c).

Figura expoente no estudo de doenças nervosas, Charcot, costumava dizer que em relação ao estudo anatômico do sistema nervoso nada mais restava a dizer; era sobre as neuroses, aqui ainda concebida como afecção dos nervos, que os estudiosos e clínicos deveriam se debruçar. Seu empenho inicial foi o de demonstrar à medicina de sua época que a afecção histérica não deveria ser desqualificada pelo saber médico, demonstrando a regularidade sintomatológica da histeria e a afastando da insígnia sob a qual fora inscrita, a saber, a da simulação (PEREIRA, 1999).

Através do estudo científico da hipnose, Charcot demonstrava em suas apresentações de doentes e conferências as indicações positivas da histeria, isto é, os sintomas somáticos, legitimando, assim, uma sintomatologia e permitindo que a afecção tivesse seu estatuto radicalmente alterado. Não era mais sob as indicações de degenerescência ou ainda através de uma sintomatologia negativa - ou seja, evidenciando aquilo que faltaria -, que se abordaria a histeria, como vinha sendo feito pela medicina 
europeia no século XIX. A partir da clínica, o médico francês confirma a autenticidade dos fenômenos histéricos através de sua produção sob a sugestão hipnótica (FREUD, 1993c).

Afirmada a legitimidade do sintoma histérico e tendo a clínica como guia, Freud passa a dedicar-se ao estudo da etiologia da histeria. Afasta-se de Charcot ao sustentar que não há qualquer vestígio de afecção motora na paralisia histérica, atestando que "a histeria se comporta como se anatomia não existisse" (FREUD, 1993d, p. 126). Os estudos de paralisias cerebrais orgânicas consideravam que a afetação das regiões seguia o caminho dos nervos, isto é, para que um dos membros ficasse paralisado, seria necessário que houvesse uma paralisia unilateral de toda a estrutura anatômica que o antecede. Freud sustentou que a paralisia histérica ocorria "por representação", que a ideia ou representação psíquica de um membro é aquilo que se dissocia, impregnada de uma grande quantidade de afeto (FREUD, 1993d).

De acordo com Freud, o afeto diz respeito a um quantum energético, que pode ser investido e desinvestido psiquicamente. A noção de afeto [Affekt] aproxima Freud dos estudos do médico vienense Josef Breuer, que utilizava a hipnose em seu método catártico. Laplanche e Pontalis (2016) destacam a importância da noção de afeto nos estudos iniciais de Breuer e Freud e o valor terapêutico que a ab-reação assume no método de Breuer. Para este, a origem do sintoma histérico era buscada em um evento traumático em relação ao qual não houve uma descarga adequada do afeto a ele relacionado. Apenas com a evocação da lembrança, sob hipnose, o afeto era reativado e poderia ser descarregado através da ab-reação. A recordação do evento traumático acompanhada da descarga do afeto correspondente permitia o desaparecimento dos sintomas. Não por acaso, Anna O., como ficou conhecida a famosa paciente de Breuer, batizou este novo método de talking cure, a cura pela palavra.

O caso Anna O. foi de grande importância para Freud a respeito da teoria da clínica, conforme afirmou em uma de suas conferências na Clark University, nos Estados Unidos: "[...] declarei então que não havia sido eu quem criara a psicanálise: o mérito cabia a Joseph Breuer, cuja obra tinha sido realizada numa época em que eu era apenas um aluno preocupado em passar nos exames" (FREUD, 2013, p.16). Apesar de Breuer ter contribuído para o surgimento da psicanálise, esta é criada quando Freud abandona o método catártico e a sugestão hipnótica, como veremos a seguir.

O método catártico pressupunha que o paciente fosse hipnotizável, supondo, ainda, que houvesse uma ampliação da consciência pela hipnose. Freud observa que em 
grande parte dos casos, não era apenas uma impressão que se encontrava na gênese do sintoma, mas, sim, diversas impressões. Esta observação acrescenta uma dificuldade, pois o método catártico supunha haver apenas uma determinação ao sintoma, que seria invariavelmente desvelada sob hipnose. Freud modifica a técnica, mas logo isto conduz a uma mudança radical em sua concepção do trabalho terapêutico: abre mão da hipnose e institui a regra fundamental do tratamento analítico: a associação livre (FREUD, 2016a).

Ao abandonar a hipnose, Freud mantém, contudo, os pacientes deitados - não mais no leito hospitalar, mas no divã, e se posiciona fora de seu campo de visão. Nesta posição de esforço muscular mínimo, pede ao paciente que fale sem preocupar-se com o conteúdo que venha a lhe ocorrer, mesmo que lhe pareça estranho ou inadequado. Eis a regra fundamental do tratamento analítico: "antes de lhes pedir um relato minucioso da história de sua doença, ele insiste em que falem tudo o que lhes passar pela cabeça, mesmo quando acharem que é insignificante" (FREUD, 2016a, p. 324).

Ao remontar aos primórdios da história da psicanálise, Freud (2012) indica três fatores que permitiram a criação de sua nova ciência a partir da modificação do método catártico: a teoria do recalque e da resistência, a teoria da sexualidade infantil e a interpretação dos sonhos como via régia para o inconsciente. Trataremos brevemente de cada um destes marcos teórico-conceituais a fim de ressaltar o interesse de investigação clínica por parte de Freud, que sustenta sua prática e teoria da clínica.

Sobre a teoria do recalque e da resistência, Freud a considerava original até deparar-se com a concepção de Schopenhauer sobre a loucura, em que afirma que ao se haver com a realidade penosa, o homem se recusa em aceitá-la. Em seguida, afirma que se privou do prazer em desfrutar a leitura das obras de Nietzsche, pois não gostaria que alguma ideia de cunho filosófico, portanto abstrato, influenciasse suas elaborações psicanalíticas, uma vez que sempre partia da clínica para a ela retornar. São observações interessantes, pois revelam que a psicanálise não se construíra fora do laço social sobretudo àquele em que se inserem os povos de língua alemã. Porém, o psicanalista faz uma ressalva: não é necessário reivindicar originalidade ou prioridade em suas ideias, pois elas estão presentes na fala de seus pacientes e apenas por meio da "laboriosa pesquisa psicanalítica" (FREUD, 2012, p. 257) foi possível confirmar determinadas percepções, sobre as quais os filósofos puderam apenas se aproximar intuitivamente. Mais uma vez, Freud afirma a precedência do método clínico de investigação na elaboração teórico-conceitual da psicanálise em detrimento de formulações abstratas, alheias ao lastro real fornecido pela prática e pela experiência clínicas. 
Freud assevera que a pedra angular da psicanálise é a teoria do recalque, sendo esta a expressão teórica de uma resistência que pode ser observada na clínica. Ao empreender um tratamento psicanalítico constata-se o aparecimento de uma força que se opõe ao seu prosseguimento, fazendo com que surja uma série de no relato do paciente. O recalque seria a força que torna inacessível à consciência o acesso a um determinado conteúdo, que, assim, é arrastado de volta ao inconsciente. O recalque se faz, assim, o operador fundamental da resistência, impedindo que o fluxo da associação livre transcorra sem obstáculos (FREUD, 2012).

A hipnose, método abandonado por Freud por justamente encobrir a resistência, evitando-a, interditava ao médico o acesso ao jogo das forças psíquicas (FREUD, 2016a). É por tal motivo que o próprio Freud considera que a história da psicanálise pode começar a ser escrita enquanto tal com o abandono da hipnose, através da adoção da regra fundamental (Grundregel) da psicanálise, a associação livre. Ao observar e tecer considerações teóricas sobre o fato observado em sua prática de que a resistência coincide com uma amnésia, Freud ruma à concepção da atividade psíquica inconsciente, distinguindo-a de qualquer especulação filosófica: "Eu me oporia energeticamente se alguém desejasse incluir a teoria da repressão e da resistência entre os pressupostos da psicanálise, em vez de entre seus resultados" (FREUD, 2012, p. 258).

Outro extrato teórico de seu minucioso trabalho clínico é a formulação da hipótese da sexualidade infantil, quando se distancia radicalmente de seus pares. Ao conduzir o tratamento sob a perspectiva de chegar à lembrança causadora da neurose Freud se encontrou com elementos que remetem aos tempos mais primordiais da infância de seus pacientes. Inicialmente, sob a influência de Charcot, Freud tendeu a buscar o substrato de verdade nas cenas de sedução, supostamente ocorridas na mais tenra idade, presentes nos relatos dos pacientes. Estes atribuíam os sintomas de que padeciam à sedução por parte de um adulto - via de regra, o pai (FREUD, 2012).

Freud abandona a teoria da sedução quando constata a improbabilidade de que os pais de todos os neuróticos fossem perversos já que a própria prática clínica não indicava uma incidência significativa de pacientes perversos. Abalado, Freud afirma não mais acreditar em sua neurotica (teoria das neuroses) em carta ao médico alemão Wilhelm Fliess, seu interlocutor privilegiado à época (MASSON, 1986). Assim, introduz a noção de fantasia como formadora dos sintomas neuróticos. As lembranças trazidas à clínica não eram falsas, mas fantasiadas - a realidade psíquica (Realität) exigia ser tomada em seu valor de efetividade (Wirklichkeit). Posteriormente, afirmou que teria todos os 
motivos para desistir do trabalho clínico, porém viu-se despojado do direito de desistir apenas porque sua expectativa não correspondeu ao dado empírico. Era preciso rever as suas expectativas (FREUD, 2012). Observa, o percurso de uma análise leva a dificuldades, sobretudo no que diz respeito à sexualidade. No entanto, qualquer obscurecimento de visão não pode ser eliminado com especulações inefáveis, devem, antes, persistir na investigação clínica.

Segundo testemunha Freud (2012), o trabalho clínico-teórico a propósito dos sonhos fora uma espécie de consolo em momentos de isolamento no meio acadêmico e científico. Muitas vezes, a comprovação de suas concepções iniciais mediante o trabalho clínico era demasiado lenta, já que não há como guiar o tratamento analítico a não ser pelo que o sujeito diz. Os sonhos, porém, permitiam que se encontrasse uma confirmação regular daquilo que afirmava em relação aos sintomas neuróticos, tomando-os por fenômenos análogos, visto que os mecanismos de formação onírica, a saber, o deslocamento e a condensação, encontram-se também na formação dos sintomas (FREUD, 2012).

Sem pares nos meios médico e científico, Freud se vê obrigado a se isolar intelectualmente, sustentando firmemente a validade de seus achados clínicos. Após sustentar na Sociedade de Psiquiatria e Neurologia de Viena suas proposições acerca da etiologia sexual das neuroses, Freud envia carta uma Fliess em que revela seu retraimento em relação a seus pares, sustentando com vigor suas descobertas clínicas mesmo após a "recepção gélida" em sua conferência. Destaca a presença de Krafft-Ebing, psiquiatra alemão conhecido por sua obra Psychopatia Sexualis, publicação de referência no estudo da sexualidade, à época. Krafft-Ebing teria afirmado, em tom pejorativo, que a apresentação realizada por Freud perante aquela sociedade médica mais parecia um “conto de fadas científico" (MASSON, 1986 p. 185).

Ainda assim, Freud não abandonou o ideal de tornar a psicanálise uma ciência reconhecida. Em 1914, testemunhou que supunha nunca ser reconhecido cientificamente visto o vazio que o cercava, mas que mantinha as esperanças de que alguém se depararia com suas concepções e alcançaria um estatuto científico à psicanálise.

\section{Pesquisa em psicanálise: a questão da experiência}

A partir da adoção do método clínico e das questões-problema que a clínica das neuroses lhe impunha, Freud sempre apostou em seu método terapêutico como sendo de 
caráter científico, sustentando essa posição com todos os esforços. Como médico e pesquisador no laboratório de Brücke, Freud conhecia a ciência e sabia perfeitamente como tal conhecimento deveria ser elaborado e produzido: através de um método, da experiência empírica e de sua aplicabilidade universal.

Em 1905, Freud apresenta o método terapêutico psicanalítico em uma conferência intitulada "Sobre a psicoterapia" (1993e). Apresenta de seu surgimento, esclarece sobre a técnica utilizada, elucida possíveis concepções equivocadas sobre esta, indicando a aplicabilidade da psicoterapia psicanalítica assim como o seu objetivo. No início da conferência, Freud trata da questão da credibilidade do seu método terapêutico por ele proposto, diante da descrença nas demais formas de psicoterapia tidas como "produto do misticismo moderno" e, ainda, como sendo "acientífica" (FREUD, 2016a, p. 244). A medicina da época baseava-se no postulado físico-químicos, sendo o conhecimento sobre o psíquico indigno de interesse por parte de um médico. Relembra que o tratamento psicoterápico não é uma invenção atual, uma vez que a atuação do médico não exclui o uso da palavra. Freud (2017) sustenta que através da palavra, como um legítimo instrumento de trabalho, pode-se atingir o psíquico ou anímico. As psiconeuroses podem ser acessadas de forma muito mais eficaz por meio do então novo método proposto por Freud, do que pelas demais formas de tratamento.

Avançando em sua argumentação, distingue o tratamento orientado pela sugestão - hipnótica ou não - e aquele próprio à psicanálise, Freud utiliza uma analogia com relação à distinção atribuída a Leonardo Da Vinci acerca do ofício do pintor e do escultor. Enquanto o pintor trabalharia per via di porre, isto é, acrescentando pigmentos à tela em branco, o escultor procederia per via di levare, extraindo da pedra bruta a escultura nela contida. A sugestão seria análoga ao método per via di porre à medida que acrescenta elementos externos ou alheios a o que está em jogo. A psicanálise, por sua vez, opera per via di levare, extraindo do relato/queixa dos pacientes os elementos que ali subjazem (FREUD, 1993e)

O tratamento per via di levare explicita o método clínico de Freud que, ao invés de preconceber formas de intervenção em nome de uma terapia ideal, ou seja, recusando a fórmula "tuto, cito, jucunde" [segura, rápida e agradável] (FREUD, 1993e, p. 339), trata do que o que brota na fala de seus pacientes, a cada vez. Assim, não há como prever o que se passará numa análise: o tratamento psicanalítico assemelha-se a um jogo de xadrez, no qual pode-se descrever os movimentos iniciais e aqueles finais; porém, seu desdobramento mantém-se sobre a imprevisibilidade das jogadas e das respostas do 
jogador. O ideal do pragmatismo científico de eficiência não está incluído no que Freud aponta como sendo o caminho da psicanálise.

Ao final de sua longa e profícua vida, Freud sustenta que a psicanálise per se é incapaz de produzir uma Weltanschaaung (visão de mundo) própria. Esta é definida como uma construção intelectual que tem por objetivo a solução das questões da existência de forma uniforme e com base numa hipótese que não deixe "nenhuma pergunta sem resposta" (FREUD, 1993f, p. 193). Distanciando-se dessa perspectiva característica da Weltanschauung, caberia à psicanálise alinhar-se a Weltanschauung científica, justamente por esta não se pretender autossuficiente, bem como não se pautar sobre a construção de sistemas fechados em si mesmos, vale dizer, completos. Ao contrário, o procedimento rigorosamente científico mantém-se aberto à refutação de suas premissas, relançando-se permanentemente em busca de novas soluções em relação aos problemas que se propõe a considerar.

Freud indica que o progresso que ocorre em um tratamento psicanalítico se dá de mesma forma daquele que caracteriza o trabalho científico. Haveria uma hipótese inicial, na qual tanto o pesquisador como o clínico depositam suas esperanças; não obstante, estas devem ser, necessariamente, contidas (FREUD, 1993f). A observação rigorosa aponta para novos problemas incitando a elaboração de novas hipóteses e conjecturas, devendose renunciar a convicções precoces e se abrir ao inesperado apresentado pelos resultados - são estes que determinam a efetividade do trabalho. Freud (1993f) destaca ser preciso "prescindir da ajuda fornecida à pesquisa, mediante a experimentação" (FREUD, 1993f, p. 211). É na própria experiência e nos efeitos clínicos recolhidos pelo trabalho que se pode extrair os frutos da pesquisa clínica.

Para Freud, ciência e psicanálise não caracterizam sistemas fechados, que partiriam de conceitos previa e abstratamente estabelecidos, com os quais se pretenderia apreender, a priori, todos os aspectos da experiência e, uma vez completos, não dariam lugar a novas descobertas. Ao contrário, a psicanálise procura extrair da própria experiência clínica a sua verdade, vislumbrando um caminho à frente apenas a partir da experiência e se mantendo sempre aberta à retificação de seus pressupostos (FREUD, 1993a). Parafraseando Goethe, afirma que o trabalho clínico implica em retornar do cinza da teoria ao verde da experiência (FREUD, 2016b, p. 271).

Conforme afirmam Fonteles, Coutinho e Hoffmann (2018), é na condição de práxis que a psicanálise pretende escutar o sujeito do inconsciente, representado por tudo aquilo que escapa, tropeça e surpreende nas experiências singulares e que, ao mesmo 
tempo, se sustenta como universal para cada um. Os autores ressaltam que este intento epistemo-metodológico revela o desejo de Freud de alinhar a psicanálise à Weltanschauung científica, através da premissa de universalidade, instituição indispensável para a produção científica ocidental.

Segundo Rotstein e Bastos (2011), é justamente sobre a dimensão da experiência que tratamento e pesquisa coincidem. Os autores remetem-se à palavra "experiência", tanto em português, quanto em alemão, "Erfahrung", ressaltando que ambas têm raízes comuns no grego e no latim, denotando o sentido de ir em direção a um lugar, deslocarse, buscar algo por meio de um atravessamento, de um avanço. Citamos os autores:

\begin{abstract}
Assim como a condição para nos deslocarmos em direção a um lugar é não nos encontrarmos neste, assim como o anseio por algo e a tentativa de obtê-lo pressupõem não estarmos em sua posse, do mesmo modo, nossos sentidos dãonos acesso a algo que não poderia ser alcançado através do exame da mera forma de nosso pensar, àquilo que, portanto, não se encontra desde sempre conosco. [...]. É o lançar-se em direção a algo que nos falta na tentativa de alcançá-lo, 'o entrar em comércio', o que designa fundamentalmente 'experiência', mas também o conhecimento obtido em tal lançar-se, que, à maneira do saber dos viajantes sobre lugares distantes, não se deixa antecipar por revelação, adivinhação ou intuição intelectual, isto é, não pode advir de outro modo que pela viagem (ROTSTEIN; BASTOS, 2011, p. 372).
\end{abstract}

Aquilo que os autores destacam aproxima a experiência freudiana da etimologia de Erfahrung. Vorsatz (2015) sublinha que "método", etimologicamente, significa “caminho percorrido". Assim, o método clínico de Freud, que supõe a experiência do inconsciente - e não o seu conhecimento -, compreende o testemunho de um percurso realizado por cada um, a cada vez.

O conceito de inconsciente (das Unbewusste) a criação maior freudiana, também pode ser traduzido como o não-sabido. O substantivo criado por Freud, grafado em maiúscula à diferença do adjetivo unbewusst, corrente no idioma alemão, é composto pela partícula de negação Un e por Bewusste. Este último termo, por sua vez, remete ao termo constientia (compreendido como saber), em latim (BALIBAR, 2014). Bewusst pode designar tanto o substantivo 'consciência', quanto a forma do verbo no particípio: 'conhecido', 'sabido'. Logo o termo substantivado cunhado por Freud, das Unbewusste, denota, para além do conceito de Inconsciente, a dimensão de algo que escapa ao domínio do saber. Não foi através do raciocínio abstrato que Freud sustentou a nova ciência por ele criada, mas, sim, por sua submissão à clínica, à experiência de lançar-se a desbravar o não-sabido.

O movimento permanente e recíproco da investigação e do tratamento encontra um ponto de coincidência na partida desta "viagem", isto é, da experiência que na 
temporalidade retroativa da psicanálise (Nachträglichkeit) se constitui partir do achado e não do buscado. Lacan recorre a um suposto dito de Picasso para sustentar a psicanálise enquanto práxis: “Eu não procuro, acho" (LACAN, 2008, p.15). Na psicanálise, pesquisa e tratamento dizem respeito ao que se encontra na clínica, por meio de caminho que apenas poderá ser formalizado a posteriori em relação ao achado, vale dizer, ao fato clínico.

É na medida em que a psicanálise caracteriza uma práxis que podemos conceber a coincidência entre psicanálise e tratamento sublinhada por Freud. No dizer de Lacan, práxis "É o termo mais amplo para designar uma ação realizada pelo homem, qualquer que ela seja, que o põe em condição de tratar o real pelo simbólico" (LACAN, 2008, p. 14.). Em relação à experiência analítica, trata-se de abordar o real - encarnado pelo sintoma - através do campo da palavra e da linguagem, vale dizer, do registro simbólico.

Inúmeras vezes em sua vasta obra, Freud evocou um episódio ocorrido durante sua estada em Paris no início de sua prática clínica. Neste, seu mestre Charcot, diante de uma plateia de ávidos estudantes e pares se viu contestado por um aluno, que negava o sintoma apresentado por uma paciente histérica pois este contradizia uma teoria corrente à época. Diante disso, Charcot afirma que são os fatos clínicos que guiam a teoria, não o contrário: "La théorie, c'est bon, mais ça n'empêche pas d'exister." (A teoria é boa, mas não impede que [o fenômeno clínico] exista) (FREUD, 1993g, p. 23). Trilhando este caminho, a clínica fundada por Freud caracteriza o próprio campo de pesquisa em psicanálise. Esta, a clínica, é soberana.

\section{A clínica como campo de prática e de pesquisa na universidade: impasses e possibilidades}

Conforme aponta Rinaldi (2011), a pesquisa é fundamental no ambiente universitário, pois, além de lugar de ensino e reprodução do conhecimento, este é um lugar de produção, e a pesquisa é o instrumento pelo qual a produção científica se faz possível. O que implica, portanto, em fazer pesquisa em psicanálise na universidade? Para encaminhar esta formulação nos remeteremos às indicações freudianas.

Ao tecer recomendações aos praticantes da psicanálise Freud menciona a pesquisa clínica, recomendando que não se deve trabalhar sobre um caso que não foi ainda concluído, prever seu desdobramento e nem os seus resultados, como exige o método e o interesse inerentes à produção científica. O procedimento psicanalítico a ser adotado seria 
a de submeter o material à teorização apenas quando o tratamento for concluído. Não obstante, afirma que "um dos méritos que a psicanálise reivindica para si é o fato de nela coincidirem pesquisa e tratamento" (FREUD, 2010a, p. 153), o que poderia soar paradoxal e mesmo contraditório. Em psicanálise, não há um campo da pesquisa e outro da prática - é na dimensão da experiência analítica que tratamento e pesquisa coincidem.

Mais de uma década depois, Freud retoma esta questão quando redige um artigo em que institui um interlocutor leigo para defender a prática da psicanálise por psicanalistas não-médicos. Neste, remete-se ao seu próprio percurso, pontuando a dimensão de descoberta indissociável do trabalho clínico e destacando que a teorização que a sustenta enquanto procedimento de caráter científico avança a partir da clínica:

Na psicanálise sempre houve um liame indissolúvel entre a cura e pesquisa; o conhecimento trazia êxito, não se podia tratar sem aprender algo de novo, não se ganhava um esclarecimento sem experimentar seu efeito benéfico. Nosso procedimento analítico é o único que mantém essa valiosa conjunção (FREUD, 2014, p. 226, grifos nossos).

Esta afirmação diz respeito a sua preocupação de que o interesse científico se sobrepusesse à clínica. Ao afirmar o laço indissolúvel entre tratamento e pesquisa, Freud indica o estatuto de práxis constitutivo da psicanálise. Situa que a psicanálise, à diferença de outras ciências, tem como material precípuo os processos psíquicos inconscientes e não pode ser abordada de outra forma que não através do relato do sujeito/paciente, mediante a experiência clínica (FREUD, 2014). Nem o ideal de produção científica, amplamente difundido no contexto universitário, nem o ideal de cura, preconizado pelas ciências médicas, estariam alinhados ao que Freud aponta como sendo próprio à psicanálise. Por um lado, observa que não é possível que o interesse científico ensurdeça a escuta do analista frente aos seus pacientes. De outro, aponta a preocupação de suprimir o interesse investigativo em detrimento do tratamento no afã da cura a qualquer preço (FREUD, 2014).

Abordando a questão por um outro viés, Freud (2010c) questiona a inserção da psicanálise na universidade, indicando que o problema deve ser colocado a partir de dois pontos de vista: o da psicanálise, clínico, e o da universidade, locus privilegiado de produção científica. Em relação ao primeiro, afirma que a inclusão da psicanálise na academia é inteiramente prescindível para o psicanalista, uma vez que sua formação se dá através da experiência e da prática clínicas, sob supervisão, bem como de seu pertencimento a um instituto de formação analítica. No que diz respeito à universidade, a questão depende do valor atribuído ao ensino da psicanálise na formação de médicos - 
hoje, também de psicólogos. Ainda que haja pontos positivos em sua inserção na universidade, Freud (2010c) ressalta que o ensino seria limitado a questões teóricas, pela própria estrutura da universidade, de forma que o estudante jamais poderia apreender o que está em jogo na psicanálise. Assim, distingue um aprender sobre de um aprender com a psicanálise (FREUD, 2010c).

Inseridas no curso de graduação em Psicologia na UERJ nos deparamos, além das diversas disciplinas obrigatórias ou eletivas cuja temática diz respeito à psicanálise, com os estágios curriculares em clínica, sendo alguns de orientação psicanalítica. Os estágios, embora envolvidos diretamente com a prática clínica, estão referenciados à estrutura acadêmica da universidade uma vez que também são considerados uma disciplina: requerem o cumprimento de uma carga horária mínima, uma avaliação sobre o desempenho acadêmico do aluno/estagiário, um tempo mínimo e máximo de estágio e a obrigatoriedade de supervisão dos casos em atendimento pelo aluno/estagiários por parte de um docente do curso de Psicologia. Conforme destacam Darriba e Pinheiro (2011), não há a própria análise como pré-requisito ao estudante universitário, o que indica que se chega à clínica na condição de estudante, não de analisante. De forma análoga, o supervisor é tomado em sua condição de professor, docente. Os autores assinalam que, ainda que haja iniciativas, tanto da parte do estudante quanto do docente, não se eliminam os efeitos de estar sob a égide da formação universitária (DARRIBA; PINHEIRO, 2011).

Como seria, então, possível conceber a prática orientada pela psicanálise no contexto universitário frente a estas questões, que podemos destacar como impasses à clínica? Consideramos desse modo pois estas fazem contraste à proposição freudiana de que em uma análise, é a clínica que guia o tratamento, não há como preestabelecer como ele ocorrerá, cabendo apenas se responsabilizar pelo que advém do trabalho clínico. Outra questão relevante é o fato do estagiário, ao final de seu estágio, receber uma nota através da avaliação pelo trabalho realizado durante o semestre letivo, o que não contribui para um trabalho propriamente clínico, pois a função de analista deve ser isenta de qualquer recompensa ou ganho e, nesse caso, a atribuição de uma nota e a aprovação na disciplina curricular que caracteriza o estágio poderiam ser consideradas como um ganho - a saber, computado sob a forma de créditos acadêmicos.

Outro ponto a destacar é o fato de que não é o estagiário que é procurado pelo usuário/cliente/paciente, mas, sim, a instituição - no caso, de ensino. Caso seja encaminhado a uma das equipes que atuam no SPA, o caso passa a estar sob a responsabilidade do estagiário e do supervisor, tendo, de partida, um término 
preestabelecido, visto que, além da duração semestral da disciplina, há a duração máxima do próprio curso de graduação em Psicologia. Contudo, Freud (2010a) afirma não ser possível estabelecer de antemão um prazo para o tratamento analítico, e citando a fábula de Esopo, indica que, em psicanálise, trata-se de caminhar, isto é, se lançar ao trabalho, sem prever onde se irá chegar.

Além disto, a relação entre o estudante/estagiário e o professor/supervisor pode contribuir para o que Freud (2010c) chama de um ensino dogmático da psicanálise, que excluiria "o verde perpétuo da experiência" (FREUD, 2016b, p. 271). Contudo, o estágio se propõe enquanto o espaço próprio para o aluno experimentar-se no lugar de terapeuta - este é o propósito da clínica-escola na qual estamos inseridas. Ainda que levando em consideração os impasses que se interpõem no sentido de um tratamento psicanalítico tout court, estes não impedem que haja um trabalho de orientação psicanalítica, advertido quanto aos seus limites e possibilidades.

Em nossa experiência, isto é, na equipe de estágio em que estamos inseridas, a reunião semanal de supervisão é proposta em dois momentos pela supervisora. Primeiramente, um estagiário fica responsável por apresentar um artigo freudiano, previamente selecionado pela professora-supervisora, havendo uma discussão a partir das questões suscitadas pelo texto e, em especial, através de suas articulações com a prática clínica. Em um segundo momento ocorre a problematização das situações clínicas trazidas por cada estagiário. Após o relato do estagiário responsável pelo acompanhamento do caso, todos se engajam no trabalho, trazendo à discussão os elementos que se destacaram para cada um, contribuindo, dessa forma, para a construção de um trabalho em equipe, efetivamente.

Ambos os momentos incluem todos os estagiários, através de uma convocação subjetiva ao trabalho que é construído no espaço da supervisão, a cada vez. Tanto os casos em atendimento pelos estagiários no SPA quanto as referências teóricas são abordados de forma a interrogar e problematizar os elementos clínicos, e não apenas n o sentido de fornecer uma orientação quanto a melhor forma de proceder. Mesmo que, em determinados momentos, algum estagiário não esteja atendendo um paciente, acompanhar a experiência do colega de equipe tem se mostrado extremamente formadora. É a partir do que o estagiário responsável pelo atendimento pôde escutar que o trabalho é encaminhado pela supervisora, e os integrantes da equipe podem colocar-se em posição de escuta em relação ao que o colega relata sobre o atendimento que realizou junto ao paciente, incluindo as suas dificuldades no manejo de cada situação clínica. Desse modo, 
construímos o trabalho em equipe, sob supervisão, isolando os elementos clínicos que se destacam de cada caso. Esse modo de operar possibilita um delineamento e um direcionamento de trabalho.

Há outro ponto relevante em nossa metodologia de trabalho: em toda reunião de supervisão, tem-se um responsável por confeccionar uma ata. A ata, além da função de registrar a discussão e as orientações relativa a cada situação clínica ou ainda institucional, caracteriza o próprio trabalho inicial da construção do caso em equipe, discriminando os elementos constitutivos de cada caso. De outra parte, o registro em ata passa a constituir um material de consulta e também de pesquisa. Uma vez que o trabalho ocorre no âmbito de universidade pública, a esta deve retornar o produto do trabalho que nela se realiza.

A construção do caso é um ponto chave na pesquisa clínica em psicanálise, como nota Figueiredo (2004). Segundo a autora, podemos utilizar alguns binômios que balizem o caminho dessa modalidade de pesquisa, dos quais destacaremos dois: 1) História-caso: A história seria o relato clínico detalhado em cenas e falas, que o praticante leva à supervisão. De outro lado, a história seria o produto, aquilo que se extrai das intervenções feitas na clínica, o que se decanta do relato, colocando em jogo aquilo que o paciente traz no vivo de sua fala e a resposta que o praticante lhe dá - e, consequentemente, os efeitos que dela advirão ou não; 2) Supervisão-construção: a discussão é o que sustenta a construção do caso enquanto ponto chave de pesquisa clínica. A construção em supervisão intenta retornar ao pesquisador/praticante sua condição de sujeito e, em um segundo momento, a apropriação deste saber, construído, em sua condição de pesquisador. Este saber é sempre um ponto de basta, parcial, que balizará o direcionamento de um trabalho (FIGUEIREDO, 2004).

O trabalho, tal como é conduzido em nossa supervisão, ressalta a co-incidência da investigação e do tratamento implicada na psicanálise. A partir de nossos primeiros passos na experiência clínica, tecemos, em equipe, o caminho investigativo que, a um só tempo, baliza nossa prática e constrói a investigação clínica de cada caso. Freud aponta que o caminho da psicanálise é único, em relação ao o qual "não existe modelo na vida real" (FREUD, 2017b, p.173). Assim, toda questão que surge na clínica é tratada a cada vez, sendo o manejo clínico sempre singular. De modo que não há uma "solução" para as questões postas pelo trabalho clínico, mas, sim, encaminhamentos que produzem efeitos singulares. 


\section{Considerações finais}

Dentre as modalidades de produção científica sobre os quais discorremos no início deste trabalho, vimos que a pesquisa em psicanálise pode ser considerada a partir de uma metodologia qualitativa. Esta se pretende diferenciada dos moldes positivistas da pesquisa quantitativa pela especificidade de seu método, que considera a subjetividade do pesquisador e objeto, ainda que ambicione a formalização de um saber. Conforme exposto, a psicanálise em sua prática e teoria da clínica não se detém apenas sobre os indicadores pragmáticos de investigação científica que atuam na visada do construto de um saber que corrobore - ou refute - uma hipótese inicial, vale dizer, de caráter meramente especulativo.

É a partir de outro lugar que a psicanálise se insere no campo científico. Ainda que não se afaste do escopo e dos paradigmas da ciência, sustenta o critério de universalidade não na generalização dos fenômenos, mas sustentando o caráter singular do fenômeno clínico. Se, conforme afirmou Freud em 1912, pesquisa e tratamento coincidem, é porque a própria psicanálise se encontra subordinada ao método clínico de investigação. A história da psicanálise, tal como o próprio Freud a constrói, é marcada pela dimensão de descoberta que a clínica impôs à investigação freudiana. A experiência de lançar-se à formulação aparentemente paradoxal de um saber não sabido, isto é, inconsciente, é a fonte primordial de suas elaborações teóricas, que sustentam a sua prática.

Enquanto integrantes de uma equipe de estágio em clínica de orientação psicanalítica na universidade, testemunhamos o estatuto indissolúvel do laço entre investigação e tratamento. Na metodologia proposta pela supervisora este laço se faz presente sob a forma de uma direção de trabalho singular, ainda que o trabalho se realize em equipe - através do qual, a um só tempo, a investigação é o pilar da direção do trabalho clínico e da construção do caso.

A prática clínica supervisionada na universidade, com suas características próprias, pode gerar impasses ao trabalho clínico propriamente dito, pois, de saída, implica em precondições estabelecidas pela estrutura acadêmica. No entanto, consideramos que orientadas pelo método clínico de Freud, seja possível um trabalho em que pesquisa e tratamento de orientação psicanalítica no meio universitário venham a coincidir, não apesar dos impasses, mas a partir deles, considerando-os como intrínsecos a esta prática clínica. 


\section{Referências}

BALIBAR, E. Consciousness. In: CASSIN, B. (Org.). Dictionary of untranslatables: a philosophical lexicon. 1. ed. Princeton: Princeton University Press, 2014.

BLANCHOT, M. A conversa infinita 1: A palavra plural. 1. ed. São Paulo: Escuta, 2010.

DARRIBA, V.; PINHEIRO, N. Psicanálise na clínica da universidade: questão ética. In: CALDAS, H.; ALTOÉ, S. (Orgs.). Psicanálise, Universidade e Sociedade. 1. ed. Rio de Janeiro: Companhia de Freud, 2011.p. 157 - 164.

FIGUEIREDO, A. C. A construção do caso clínico: uma contribuição da psicanálise à psicopatologia e à saúde mental. Revista Latinoamericana de psicopatologia fundamental, São Paulo, v. VII, n. 1, p.75-86, mar. 2004.

FONTELES, C. S. L., COUTINHO, D. M. B.; HOFFMANN, C. A pesquisa psicanalítica e suas relações com a universidade. Ágora - Estudos em Teoria Psicanalítica, Rio de Janeiro, v. XXI, n.1, p. 138-148, jan./abr. 2018.

FREUD, S. Dois verbetes de enciclopédia. In: SALOMÃO, J. (Org.). Obras Completas de Sigmund Freud: Vol. XVIII. 2. ed. Rio de Janeiro: Imago, 1993a. p. 243 -268.

FREUD, S. Interpretação dos Sonhos. In: SALOMÃO, J. (Org.) Edição Standard Brasileira das Obras Completas de Sigmund Freud: Vols. IV e V. 2. ed. Rio de Janeiro: Imago, 1993b. s.p.

FREUD, S. Relatório sobre meus estudos em Paris e Berlim. In: SALOMÃO, J. (Org.). Edição Standard Brasileira das Obras Completas de Sigmund Freud: Vol. I. 2. ed. Rio de Janeiro: Imago, 1993c. p. 35-49.

FREUD, S. Algumas considerações para um estudo comparativo das paralisias motoras orgânicas e histéricas. In: SALOMÃO, J (Org.). Edição Standard Brasileira das Obras Completas de Sigmund Freud: Vol. I. 2. ed. Rio de Janeiro: Imago, 1993d. p. 201-220.

FREUD, S. Sobre a psicoterapia. In: Edição Standard Brasileira das Obras Completas de Sigmund Freud: Vol. VII. $2^{a}$ Edição. Rio de Janeiro: Imago, 1993e. p. 241-254.

FREUD, S. A questão da Weltanschauung. In: SALOMÃO, J. (Org.). Edição Standard Brasileira das Obras Completas de Sigmund Freud: Vol. XXII. 2. ed. Rio de Janeiro: Imago, 1993f. p. 155-177.

FREUD, S. Charcot. In: SALOMÃO, J. (Org.). Edição Standard Brasileira das Obras Completas de Sigmund Freud: Vol. I. 2. ed. Rio de Janeiro: Imago, 1993g. p. 17-32.

FREUD, S. O início do tratamento. In: SOUZA, P.C. (Org.). Obras Completas de Sigmund Freud: Vol. X. 1. ed. São Paulo: Companhia das Letras, 2010a. p. 163 -192.

FREUD, S. Os instintos e seus destinos. In: SOUZA, P. C. (Org.). Obras Completas de Sigmund Freud: Vol. XII. 1. ed. São Paulo: Companhia das Letras, 2010b. p. 51 - 98.

FREUD, S. Deve-se ensinar psicanálise nas universidades? In: SOUZA, P. C. (Org.). Obras Completas de Sigmund Freud: Vol. XIV. 1. ed. São Paulo: Companhia das Letras, 2010c. p. $377-381$. 
FREUD, S. Cinco lições de Psicanálise. In: SOUZA, P. C. (Org.). Obras Completas de Sigmund Freud: Vol. IX. 1. ed. São Paulo: Companhia das Letras, 2013. p. 220 - 286.

FREUD, S. Contribuição à história do movimento psicanalítico. In: SOUZA, P.C. (Org.). Obras Completas de Sigmund Freud: Vol. XI. 1. ed. São Paulo: Companhia das Letras, 2012. p. $245-327$.

FREUD, S. A questão da análise leiga: diálogo com um interlocutor imparcial. In: SOUZA, P. C. (Org.). Obras Completas de Sigmund Freud: Vol. XVII. 1. ed. São Paulo: Companhia das Letras, 2014. p. $124-230$.

FREUD, S. O método psicanalítico de Freud. In: SOUZA, P.C. (Org.). Obras Completas de Sigmund Freud: Vol. VI. 1. ed. São Paulo: Companhia das Letras, 2016a. p. 321 - 330.

FREUD, S. Neurose e psicose. In: IANNINI, G.; TAVARES, P. H. (Orgs.). Obras incompletas de Sigmund Freud: Neurose, psicose e perversão. 1. ed. Belo Horizonte: Autêntica Editora, 2016b. p. $271-278$.

FREUD, S. Tratamento psíquico ou anímico. In: IANNINI, G.; TAVARES, P.H. (Orgs.). Obras incompletas de Sigmund Freud: Fundamentos da clínica. 1. ed. Belo Horizonte: Autêntica Editora, 2017a. p. 19 - 46.

FREUD, S. Observações sobre o amor transferencial. In: IANNINI, G; TAVARES, P. H. (Org.). Obras Incompletas de Sigmund Freud: Fundamentos da clínica psicanalítica. 1. ed. Belo Horizonte: Autêntica Editora, 2017b. p. 165 - 182.

GERHARDT, T. E.; SOUZA, A. C. Aspectos Teórico-conceituais. In: GERHARDT, T.; SILVEIRA, D. (Orgs.). Métodos de Pesquisa. 1. ed. Porto Alegre: Editora da UFRGS, 2009. p. 11-29.

LACAN, J. O Seminário, Livro 11: Os quatro conceitos fundamentais da psicanálise. 2. ed. Rio de Janeiro: Zahar, 2008.

LAPLANCHE, J.; PONTALIS, J. B. Afeto. In: Vocabulário de Psicanálise. 4. ed. São Paulo: Martins Fontes, 2016.

LOPES, A. Psicanálise Universidade: conexões possíveis. In: CALDAS, H.; ALTOÉ, S. (Org.). Psicanálise, Universidade e Sociedade. 1. ed. Rio de Janeiro: Companhia de Freud, 2011. p. $133-142$.

MASSON, J. M. A correspondência completa de Sigmund Freud para Wilhelm Fliess (1887-1904). 1. ed. Rio de Janeiro: Imago, 1986.

PEREIRA, M. C'est toujours la même chose: Charcot e a descrição do Grande Ataque Histérico. Revista Latinoamericana de psicopatologia fundamental, São Paulo, v. II, n. 3, p. 159-165, juil./ sept. 1999.

PINTO, E. B. A pesquisa qualitativa em psicologia clínica. Psicologia USP, São Paulo, v. 15, n. 1-2, p. 71-80, 2004.

PRUDENTE, R. C. A. C.; RIBEIRO, M. A. C. Psicanálise e ciência. Psicol. cienc. prof., Brasília, v.25, n.1, p.58-69, mar. 2005. 
RINALDI, D. Psicanálise e saúde mental: a pesquisa na universidade. In: CALDAS, H.; ALTOÉ, S. (Org.). Psicanálise, Universidade e Sociedade. 1. ed. Rio de Janeiro: Companhia de Freud, 2011. p.175 - 184.

ROTSTEIN, E.; BASTOS, A. A concepção freudiana de experiência. Rio de Janeiro, v. 27 n. 3, p. 371-380, 2011.

SILVA, S. A.; HERBERG, E.; MATOS, L. A. L. Características da inserção da psicologia nas pesquisas clínico-quantitativas: uma revisão. Boletim de psicologia, São Paulo, v. LXV, n 142, p. 97-111, jan. 2015.

SILVEIRA, D. T.; CÓRDOVA, F. P. A pesquisa científica. In: GERHARDT, T.; SILVEIRA, D. (Orgs.). Métodos de Pesquisa. 1. ed. Porto Alegre: Editora da UFRGS, 2009. p. 31-42.

VORSATZ, I. O sujeito da psicanálise e o sujeito da ciência: Descartes, Freud e Lacan. Psicol. Clin., Rio de Janeiro, v. 27, n. 2, p. 249 - 273, 2015.

Recebido em: 31 de janeiro de 2018.

Aceito em: 28 de julho 2018. 